Clemson University

TigerPrints

\title{
$5-2013$
}

\section{Exploring Interactive Writing as an Effective Practice for Increasing Head Start Students' Alphabet Knowledge Skills}

\author{
Anna H. Hall \\ Clemson University, ah2@clemson.edu \\ Michael D. Toland \\ University of Kentucky \\ Jennifer Grisham-Brown \\ University of Kentucky \\ Steve Graham \\ Arizona State University
}

Follow this and additional works at: https://tigerprints.clemson.edu/eugene_pubs

Part of the Education Commons

\section{Recommended Citation}

Hall, A.H., Toland, M.D., Grisham-Brown, J. et al. Exploring Interactive Writing as an Effective Practice for Increasing Head Start Students' Alphabet Knowledge Skills. Early Childhood Educ J 42, 423-430 (2014). https://doi.org/10.1007/s10643-013-0594-5

This Article is brought to you for free and open access by the Eugene T. Moore School of Education at TigerPrints. It has been accepted for inclusion in Publications by an authorized administrator of TigerPrints. For more information, please contact kokeefe@clemson.edu. 
Exploring Interactive Writing as an Effective Practice for Increasing Head Start Students' Alphabet Knowledge Skills

Interactive writing is a teaching strategy supported by both social constructivist theory (Vygotsky 1978) and the emergent literacy approach (Clay 1975) that allows children and teachers to "share the pen" during writing lessons to create group texts. Vygotsky posited that a child's cognitive development occurs through interactions with peers and adults. He coined the term "zone of proximal development" which describes a child's need for scaffolding to advance to the next learning stage. Support is tapered as it becomes unnecessary until the child is independent with the new skill (Vygotsky 1978). Due to the social nature of the interactive writing process and the vital role of the teacher as facilitator, Vygotsky's social constructivist theory best describes the theoretical foundation for this instructional strategy.

Marie Clay coined the term “emergent literacy” around the same time span as Vygotsky's work on social constructivist theory. Clay proposed that children develop literacy skills through meaningful experiences in which they are able to actively construct knowledge and practice new vocabulary within a social context. She described children developing literacy skills at different rates, along a developmental continuum, and without a set sequence of activities (Clay 1975, 1987, 1998; Howell 2008). Today, a strong research base exists recommending the use of the emergent literacy approach, which incorporates strategies that integrate reading and writing skills (Katims 1994; McNamara,Vervaeke, \& Lankveld 2008; Parodi 2007; Skeans 2000).

During interactive writing the teacher offers varying levels of support and children are invited to take an active role in the writing process. The teacher, along with multiple children, writes the letters and words of the group text. The teacher makes decisions about appropriate guidance based on each child's current level of engagement with the text (Rubadue 2002). The 
strategy allows teachers to individualize instruction during lessons based on each child's individual age, needs, and ability level. As children go through the steps of an interactive writing lesson, they are introduced to a variety of important emergent literacy skills within an authentic writing experience. Advocates of interactive writing maintain that by basing instructional decisions on the development and progress of each child, children are likely to develop a level of understanding that will support their applications of literacy skills in future contexts (Craig 2003; McCarrier, Pinnell, \& Fountas 2000).

\section{Alphabet Knowledge}

Although all emergent literacy skills are important for building a strong foundation for future reading and writing, alphabet knowledge is consistently described in the literature as a key predictor of future literacy success (Foy \& Mann 2006; Lonigan \& Shanahan 2009; National Association for the Education of Young Children \& International Reading Association 1998; Snow, Burns, \& Griffin 1998; U.S. Department of Health and Human Services 2003; Vellutino \& Scanlon 2001; Whitehurst \& Lonigan 1998). For instance, the National Early Literacy Panel (NELP) found in their meta-analysis of literacy research evidence that alphabet knowledge yielded stronger relationships with later skills in decoding, reading comprehension, and spelling than other early literacy skills examined in the report (e.g., phonological awareness, phonological memory, rapid automatic naming of letters; Lonigan \& Shanahan 2009).

\section{Current Study}

Although studies exist showing the utility of interactive writing in kindergarten and the primary grades, there is a lack of experimental research regarding the effectiveness of this strategy in the preschool setting and in relationship to alphabet knowledge skills (Campbell 
1998; Howell 2008; Scrivens 1998;). The current study examines whether participation in interactive writing relates to increases in students' abilities to identify upper case letters, lower case letters, and letter sounds.

\section{Method}

The study used a pretest-posttest randomized control group design with 73 Head Start students, ages 3-5 years. The two groups were similar in gender, age, ethnicity, disability status, time spent in program, and absenteeism rate. The researcher, a certified early childhood teacher, delivered the intervention to the treatment group, rotating to five different classrooms in one Head Start center 3-4 days a week for 13 weeks. Children in the treatment group received a 1015 minute interactive writing lesson each day in small groups within their own classroom settings. Participants were randomly assigned to either the treatment $(n=36)$ or control group ( $n$ =37) within each classroom. Randomization occurred prior to any data collection.

\section{Instruction}

Intervention received by treatment group. During the regularly scheduled small group time within each of the five classrooms, students from the treatment group rotated between two small groups. One small group focused on the interactive writing lesson and the other small group focused on an art or science activity. During each interactive writing lesson, the teacher and students: (1) discussed and negotiated the class writing topic, (2) talked about letters, sounds, and words while dictating and writing the text, (3) read and reread sentences as the text was constructed, and (4) decided where to place the text so it could be read and reread later for enjoyment (McCarrier et al., 2000). Lessons were selected from Interactive Writing \& Interactive Editing: Making Connections between Writing and Reading by Swartz et al. (2002) 
and Interactive Writing: How Language and Literacy Come Together, $\mathrm{K}-2$ by McCarrier et al. (2000) and were tailored to focus on alphabet knowledge skills and the children's interests. Lessons were adapted for children needing extra support by providing additional modeling and hand-over-hand assistance. The researcher provided picture cues to assist English Language Learners and required physical responses to check for comprehension (e.g., thumbs up, repeating the answer, head nod).

Standard instruction received by control group. The control group did not receive any treatment or intervention from the researcher. The control group only participated in data collection including the pre/post child outcome measures of alphabet knowledge skills. During small group time, the control group rotated to two small groups including their standard literacy instruction (Creative Curriculum) and an art or science activity. The Creative Curriculum literacy activities were different in each of the five classrooms each day, but all lessons either consisted of a single activity or combination of activities that included songs, rhymes, finger plays, movement activities, and/or read alouds.

\section{Measures.}

OSELA. The Letter Identification Task, a subtest of the Observation Survey of Early Literacy Achievement (OSELA; Clay 2002), was used to measure upper case, lower case, and letter sound identification for the study. Although the OSELA was designed as a comprehensive assessment (comprised of six subtests) to measure early reading skills of 5-7 year olds, the Letter Identification task has been recognized by the field as an appropriate subtest to be used with children ages 3-5 years (Craig 2006; Foy \& Mann 2006; Jones, Reutzel, \& Fargo 2010; Westburg, McShane, \& Smith 2006). Based on administration guidelines, the measurement task 
for each part of the test administration was discontinued after eight incorrect answers (Foy \& Mann 2006). Reliability coefficients have been reported to range from .97 (Clay 2002) to .95 (Pinnell, McCarrier, \& Button, 1990). Based on the sample in the current study, Cronbach's coefficient alpha for pretest scores was .96 for upper case letter identification, .95 for lower case letter identification, and .94 for letter sound identification. Cronbach's coefficient alpha for posttest scores was .96 for upper case letter identification, .96 for lower case letter identification, and .97 for letter sound identification.

\section{Data Analysis}

To address the primary hypothesis, separate ANCOVAs were initially proposed and power analyses were conducted for scores on each child outcome variable with respective pre scores as a covariate. However, preliminary analyses showed child outcomes (e.g., number of letters/sounds identified) were not normally distributed within groups because of the high frequency (count) of zero's occurring on outcomes. In essence, each outcome had a pile of zeros, followed by some distribution.

Given the high frequency of zeros (count) on each of the primary outcomes, groups were compared on each outcome controlling for pre scores by implementing a zero-inflated Poisson (ZIP) regression model. Parameters in the ZIP model were estimated with maximum likelihood with robust standard errors. In addition, a two-step approach was adopted (see Vazsonyi \& Keiley 2007; Muthén \& Muthén 1998-2010 for similar approaches in longitudinal modeling) to examine differences across groups on child outcomes after controlling for pre scores. This twostep approach was conducted for each child outcome; allowing detection of the approximate 
normal distributional shape of the non-zero child outcome scores and to add to the interpretability of the results.

The data analytic approach used in this study allowed an intent-to-treat analysis (ITT) and did not allow results to be biased by a complete case analysis. Furthermore, implementing an ITT analysis, properly handling missing data, and addressing non-normality improved statistical conclusion validity (Shadish, Cook, \& Campbell 2002). Finally, it is important to mention that in our sample complete case analyses did not differ from our final analyses using missing data techniques, further improving the statistical conclusion validity of our results

\section{Results}

\section{Child outcomes}

First, a ZIP regression analysis was performed to compare interactive writing to the control group on each child outcome (frequency of correct responses) after controlling for pre scores on respective outcomes. Table 1 summarizes the results for the ZIP models. An inspection of Table 1 shows a statistically significant difference between interactive writing and the control group was only observed on post lower case identification skills (coeff. $=.19, p=$ .03 ) and post upper case identification skills (coeff. $=.16, p=.04$ ), after controlling for pre scores on respective outcomes.

Specifically, if a child did not have zero on the post outcome, the expected number of additional lower case letters that will be identified by children in the interactive writing group is $\exp (.19)=1.21$ times the expected number of lower case letters that will be identified by children in the control group, holding pre scores constant. When we examine the intercept for 
post lower case identification skills, we can see that children in the control group are expected to have about $\exp (2.10)=8.17$ lower case letters identified, holding pre scores constant.

Taking these estimates into consideration we can determine that the expected number of post lower case letters identified by children in the interactive writing group is $\exp (2.10+.19)=$ 9.88, holding pre scores constant. On average, the interactive writing group identified almost two more lower case letters compared to the control group, holding pre scores constant. Similarly, for post upper case identification skills, we see the expected number of upper case letters identified by children in the control group is $\exp (2.18)=8.85$ and for children in the interactive writing group is $\exp (2.18+.16)=10.38$, for a difference of a little over one more upper case letter identified. In addition, an inspection of Table 1 shows that pre scores on each respective outcome were positively predictive of post scores for children with non-zero scores on outcomes.

\section{$<$ INSERT TABLE 1>}

Next, a binary logistic regression analysis was performed to compare interactive writing to the control group on each child outcome $(0=$ zero skills or skill not observed, $1=$ non-zero skill or skill observed) after controlling for pre scores on respective outcomes. A test of the full model to the null model was statistically significant for all three outcomes, post lower case identification, $F(2,4266.78)=12.95, p<.001$, post upper case identification, $F(2,4385.42)=$ $9.30, p<.001$, and post letter sound identification, $F(2,1649.73)=12.90, p<.001$. Table 2 summarizes the binary logistic regression analyses. Inspection of Table 2 indicates that there was not a statistically significant difference between the interactive writing and control group on 
any of the binary outcomes, but the odds ratio $(\operatorname{Exp}[\mathrm{B}])$ comparing these two groups on post letter sound identification was 2.2.

Although not statistically significant, in practical terms, it means the expected odds of having a non-zero letter sound identification score for those in interactive writing was a little more than twice as large as the odds of those in the control group, holding pre scores constant. Interestingly, the opposite phenomenon was observed for post upper case identification, which means the expected odds of having a non-zero upper case identification score was larger for children in the control group than in the interactive writing group. In addition, the logistic regression results show pre scores for lower case and upper case identification skills are predictive of children having non-zero lower case and upper case scores, respectively (see Table 2). Thus, the higher the pre score, the higher the odds of non-zero scores on lower case and upper case.

\section{<INSERT TABLE 2>}

Finally, multiple regression analyses predicting post child outcomes for those with nonzero scores from group membership and pre scores on respective outcomes. Table 3 summarizes the multiple regression analyses. The last two columns of Table 3 display the model explained variability (multiple $R^{2}$ ) along with its associated $p$ value. These overall model results indicate the multiple $R^{2}$ statistic obtained from the entire set of predictors is statistically significant. Further inspection of Table 3 shows no statistically significant difference between the interactive writing and control group on any of the outcomes, but the effect size comparing groups on post lower case identification is notable $(\mathrm{ES}=$ coeff $/ \sqrt{ }$ residual variance $=2.65 / \sqrt{ } 31.36=.48)$. This means children in the interactive writing group who had non-zero scores on lower case 
identification skills improved by about half a standard deviation relative to students in the control group.

Similarly, a small effect size $(\mathrm{ES}=1.59 / \sqrt{2} 27.21=.30)$ was found between the groups on the non-zero scores for upper case identification skills (see Table 3). For letter sound identification, the effect size was trivial $(\mathrm{ES}=0.17 / \sqrt{ } 44.60=.03)$. These effect sizes fall in line with the effects observed with the zip regression analyses. In addition, results show that pre scores on each respective outcome were positively predictive of post scores for students with non-zero scores on outcomes.

\section{$<$ INSERT TABLE 3>}

\section{Discussion}

The current study was conducted to determine the influences of interactive writing on Head Start children's alphabet knowledge skills. The pretest-posttest randomized control group design allowed researchers to explore preliminary patterns in the data. Importantly, the analyses provide conservative effect sizes for determining statistical power or predicting the appropriate sample size for larger scale studies involving preschool-age children attending Head Start. In addition, this is the first study to our knowledge to provide effect size estimates on lower case identification, upper case identification, and letter sound identification with this population using interactive writing compared to traditional Head Start literacy instruction.

Preliminary patterns. ZIP regression results showed statistically significant results favoring the interactive writing group vs. the control for lower and upper case identification. Specifically, based on the ZIP regression analyses, on average, the interactive writing group identified almost two more lower case letters and one more upper case letter compared to the 
control group. These differences reflect raw metric effect sizes of 2 more lower case letters and 1 more upper case letter identified. Although the multiple regression results for comparing groups were not statistically significant, they too were consistent with the ZIP regression analyses in highlighting the differences among the groups on these two outcomes based on the observed effect sizes.

Although effect sizes for this study might be considered small, it is important to interpret them as relative to the specific content being studied (i.e., alphabet knowledge). The raw effect sizes found in this study demonstrated that children in the interactive writing group identified about 1 to 2 more lower case letters or upper case letters above that of children in the control group over the 43 days (about 13 weeks) of intervention, which involved a mere 10-15 minutes per lesson for about 3-4 days a week (up to a total of 13 hours of instructional time). These small to moderate effects could possibly have been influenced by the high quality of "business as usual instruction" at the participating Head Start center. The selected center was awarded a four star rating from the STARS for KIDS NOW quality rating system which is the highest possible quality rating score in the sampled Southeastern state (Child Trends 2010).

To further understand the importance of observed differences between the two groups in this study, it is crucial to know the established goals of Head Start with regards to alphabet knowledge skills. In 1998, legislation established standards for Head Start requiring that all students learn at least 10 letters of the alphabet by the time they graduate from the 18 month (i.e., two-school year) program (National Head Start Association 1998). The revised Child Development and Early Learning Framework released in 2010 does not describe a specific number of letters that graduates should identify, but includes a more general statement "identifies 
letters and associates correct sounds with letters" (U.S. Department of Health and Human Services 2010, p. 15). When we examine Table 1, we can see that on average children in the interactive writing group have learned how to identify about 9.88 lower case letters and 10.38 upper case letters vs. 8.17 and 8.85 for the control group, respectively, after only 13 weeks. It is not surprising that larger observed differences and effect size were observed for lower case and upper case letter identification than for letter sound identification. Alphabet knowledge requires children to understand the names and sounds made by letters of the alphabet which are two separate yet interconnected components of the alphabetic principle (Bradley \& Jones 2007; McBride-Chang 1999). Letter naming abilities have been found to uniquely predict later literacy skills (Piasta, Purpura, \& Wagner 2009; Schatschneider, Francis, Carlson, Fletcher, \& Foorman 2004) and help children acquire letter sound knowledge (Evans, Bell, Shaw, Moretti, \& Page 2006; Justice, Pence, Bowles, \& Wiggins 2006; McBride-Chang 1999; Piasta et al. 2009).

Limitations. Even though findings from this study show modest evidence favoring interactive writing among preschoolers, some issues should be kept in mind when interpreting these findings. First, it was difficult to determine the appropriate sample size for the current study in order to detect anything but the strongest effects on account of a limited amount of previous research and most research based on older children (e.g., kindergarten). Similarly, the short time period for the intervention was another threat to the external validity of the current study. Although the allotted timeline of 13 weeks for treatment was within average limits for detecting significant results, the amount of learning that children could experience during this timeframe was limited. Additionally, the current study relied on children receiving daily 
instruction in interactive writing to increase their alphabet knowledge skills. Children with high absenteeism rates or children who withdrew from the program during the intervention threatened the internal validity of the study. Four children withdrew from the study for reasons unrelated to their participation in the study (i.e., they moved to a new school district).

\section{Future Research}

Because there is always the possibility with educational research that the findings may be influenced by factors other than the independent variable, a larger study should be administered by trained teachers at multiple Head Start Centers using a nested research design (students nested with teachers/classroom/centers). Within a nested design, additional data collection instruments will be needed to account for teacher and classroom influences as well as the effects of the home literacy environment. Such a study should consider collecting data on classroom interactions using The Classroom Assessment Scoring System (CLASS; Pianta, LaParo, \& Hamre 2007) and on the home literacy environment using a family questionnaire. Additionally, given the high frequency of zeros observed among preschool-age children on the outcomes in our sample, larger studies should wisely consider choosing the best distributional model during the data modeling process (see Gray 2005, for an example).

Finally, interactive writing should be presented to teachers within the theoretical framework of social constructivism and the emergent literacy approach. Teachers should be taught the general steps of an interactive writing lesson and the need for consistency and fidelity in following the steps during each lesson while, simultaneously, gaining an understanding of the fluidity of interactive writing and the necessity for adapting the lessons to the students' abilities 
and interests. Additionally, teachers should be trained to encourage rereading of group texts throughout the school day and to connect class projects and activities with writing themes.

Other considerations. Another issue to consider is whether future studies would be feasible and cost-effective. Because Head Start teachers are required to attend at least 15 clock hours of professional development per year, future studies could conduct workshops during these regularly scheduled training sessions. These teacher trainings would be cost-effective due to the high trainer-participant ratio. Through large-group trainings, the trainer could also have a potential impact on the teaching behaviors of numerous teachers, and therefore indirectly impact writing instruction provided to numerous children. Data collected from the current study and future studies may assist Head Start leaders in designing professional development opportunities to meet performance standards. By addressing a key concern of Head Start, to provide quality literacy instruction for young students, the results may also inform policy makers about an effective and efficient way to promote academic readiness.

\section{Conclusions}

In the new era of accountability and the No Child Left Behind (NCLB) act, attitudes about preschool have begun to shift and the view of the educational purpose and potential of preschool education has increased (Copple \& Bredekamp 2009). Given the emphasis of emergent literacy instruction in recent legislation and federally funded programs (Jackson et al. 2007; Lonigan \& Shanahan 2009), interactive writing may be an important addition to the existing Head Start literacy curriculum. While continued evaluation of the interactive writing strategy is needed in the preschool setting, the evidence from the current study shows encouraging trends in alphabet knowledge skill development as a result of this strategy. 


\section{References}

Bradley, B. A., \& Jones, J. (2007). Sharing alphabet books in early childhood classrooms. Reading Teacher, 60, 452-463. doi:10.1598/RT.60.5.5

Campbell, R. (1998). Looking at literacy learning in preschool settings. In R. Campbell (Ed.), Facilitating preschool literacy (pp. 70-83). Newark, DE: International Reading Association, Inc.

Child Trends (2010). Kentucky STARS for KIDS NOW: QRS profile. The child care quality rating system (QRS) assessment. Retrieved from http://ezproxy.uky.edu/login?url=http://search.proquest.com/docview/742855017?accountid =11836; http://www.acf.hhs.gov/programs/opre/cc/childcare_quality/kentucky/kentucky.pdf

Clay, M. M. (1975). What did I write? Beginning writing behavior. Portsmouth, NH: Heinemann.

Clay, M. M. (1987). Writing begins at home: Preparing children for writing before they go to school. Portsmouth, NH: Heinemann.

Clay, M. M. (1998). By different paths to common outcomes. York, ME: Stenhouse Publishers.

Clay, M. M. (2002). An observation survey of early literacy achievement (2nd ed.). Portsmouth, NH: Heinemann.

Copple, C., \& Bredekamp, S. (2009). Developmentally appropriate practice in early childhood programs serving children from birth through age 8. (3rd ed.). Washington, D.C.: National Association for the Education of Young Children. 
Craig, S. A. (2003). The effects of an adapted interactive writing intervention on kindergarten children's phonological awareness, spelling, and early reading development. Reading Research Quarterly, 38, 438-440. doi: 10.1598/rrq.38.4.1

Craig, S. A. (2006). The effects of an adapted interactive writing intervention on kindergarten children's phonological awareness, spelling, and early reading development: A contextualized approach to instruction. Journal of Educational Psychology, 98, 714-731. doi:10.1037/0022-0663.98.4.714

Evans, M.A., Bell, M., Shaw, D., Moretti, S., \& Page, J. (2006). Letter names, letter sounds, and phonological awareness: An examination of kindergarten children across letters and of letters across children. Reading and Writing, 19, 959-989. doi:10.1007/s11145-006-9026$\mathrm{X}$

Foy, J. G., \& Mann, V. (2006). Changes in letter sound knowledge are associated with development of phonological awareness in pre-school children. Journal of Research in Reading, 29(2), 143-161. doi:10.1111/j.1467-9817.2006.00279.x

Gray, B. R. (2005). Selecting a distributional assumption for modeling relative densitives of benthic macroinvertebrates. Ecological Modelling, 185, 1-12.

Howell, M. (2008). Interactive writing in preschool: A qualitative study of a literacy coach, two preschool teachers, and four-year-old children (Master's thesis). Retrieved from http://proquest.umi.com/pqdweb?did=1610868861\&Fmt=7\&clientId=47297\&RQT=309 $\& \mathrm{VName}=\mathrm{PQD}$

Jackson, R., McCoy, A., Pistorino, C., Wilkinson, A., Burghardt, J., Clark, M., . . Swank, P. (2007). National evaluation of early reading first. Final report to congress. NCEE 2007- 
4007 Washington, D.C.: National Center for Education Evaluation and Regional Assistance.

Jones, C. D., Reutzel, D. R., and Fargo, J. (2010). Comparing two methods of writing instruction: Effects on kindergarten students' reading skills. The Journal of Educational Research, 103 (5) 327. doi:10.1080/00220670903383119

Justice, L. M., Pence, K., Bowles, R. B., \& Wiggins, A. (2006). An investigation of four hypotheses concerning the order by which 4-year-old children learn the alphabet letters. Early Childhood Research Quarterly, 21, 374-389. doi:10.1016/j.ecresq.2006.07.010

Katims, D.S. (1994). Project IEP: An emergent literacy approach to preschool special education. Their World, 19-22.

Li, K. H., Meng, X. L., Raghunathan, T. E. and Rubin, D. B. (1991). Significance levels from repeated $p$ values from multiply imputed data. Statistica Sinica, 1, 65-92.

Lonigan, C. J., \& Shanahan, T. (2009). Executive summary: Developing early literacy: Report of the National Early Literacy Panel. Retrieved from http://lincs.ed.gov/publications/pdf/NELPSummary.pdf

McBride-Chang, C. (1999). The ABCs of the ABCs: The development of letter-name and lettersound knowledge. Merrill-Palmer Quarterly, 45, 285-308.

McCarrier, A., Pinnell, G.S., \& Fountas, I.C. (2000). Interactive Writing: How language and literacy come together, $K$-2. Portsmouth, NH: Heinemann.

McNamara, J. K., Vervaeke, S., Van Lankveld, J. (2008). An exploratory study of emergent literacy intervention for preschool children with language impairments. Exceptionality Education Canada, 18, 19-32. 
National Association for the Education of Young Children \& International Reading Association (1998). Learning to read and write: Developmentally appropriate practices for young children. Young Children, 53, 3-46.

Parodi, G. (2007). Reading-writing connections: Discourse-oriented research. Reading and Writing, 20, 225-250. doi:10.1007/s11145-006-9029-7

Pianta, R.C., LaParo, K.M., \& Hamre, B.K. (2007). Classroom Assessment Scoring System (CLASS) manual, PreK. Baltimore, MD: Paul Brookes.

Piasta, S. B., Purpura, D. J., \& Wagner, R. K. (2009). Fostering alphabet knowledge development: A comparison of two instructional approaches. Reading and Writing, 23(6), 607-626. doi:10.1007/s11145-009-9174-x

Pinnell, G. S., McCarrier, A., \& Button, K. (1990). Constructing literacy in urban kindergartens: Progress report on the kindergarten early literacy project. Report No. 10 (MacArthur Foundation). Columbus, OH: Ohio State University.

Rubadue, M. (2002). Sharing the pen. Teaching PreK-8, 32, 58-60.

Schatschneider, C., Fletcher, J. M., Francis, D. J., Carlson, C. D., \& Foorman, B. R. (2004). Kindergarten prediction of reading skills: A longitudinal comparative analysis. Journal of Educational Psychology, 96, 265-282. doi:10.1037/0022-0663.96.2.265

Scrivens, G. (1998). Nursery children as emerging readers and writers. In R. Campbell (Ed.), Facilitating preschool literacy (pp. 169-191). Newark, DE: International Reading Association, Inc.

Shadish, Cook, \& Campbell, (2002). Experimental and quasi-experimental designs for generalized causal inference. Boston, PA: Houghton-Mifflin. 
Skeans, S. S. (2000). Reading...with pen in hand! English Journal, 89, 69-72. doi: $10.2307 / 821987$

Snow, C. E., Burns, M. S., \& Griffin, P. (Eds.). (1998). Preventing reading difficulties in young children. Washington, D.C.: National Research Council.

Swartz, S. L., Klein, A. F., \& Shook, R. E. (2002). Interactive writing \& interactive editing: Making connections between writing and reading. Carlsbad, CA: Dominie Press, Inc.

U.S. Department of Health and Human Services, Administration on Children, Youth, and Families/Head Start Bureau. (2003). The Head Start path to positive child outcomes. Retrieved from http://purl.access.gpo.gov/GPO/LPS108853

U.S. Department of Health and Human Services. (2010). The Head Start child development and early learning framework. Retrieved from http://purl.access.gpo.gov/GPO/LPS108853

Vazsonyi, A. T., \& Keiley, M. K. (2007). Normative development trajectories of aggressive behaviors in African American, American Indian, Asian American, Caucasian, and Hispanic children and early adolescence. Journal of Abnormal Child Psychology, 35, 1047-1062. doi:10.1007/s10802-007-9154-z

Vellutino, F. R., \& Scanlon, D. M. (2001). Emergent literacy skills, early instruction, and individual differences as determinants of difficulties in learning to read: The case for early intervention. In S. B. Neuman \& D. K. Dickson (Eds.), Handbook of early literacy research (pp. 295-321). New York: Guilford Press.

Vygotsky, L. S. (1978). Mind in society: The development of higher psychological processes. Cambridge, MA: Harvard University Press. 
Westburg, L., McShane, S., \& Smith, L. (2006). Verizon life span literacy matrix: Relevant outcomes, measures, and research-based practices and strategies. Washington, D.C.: National Center for Family Literacy.

Whitehurst, G. J., \& Lonigan, C. J. (1998). Child development and emergent literacy. Childhood Development, 69, 848-872. doi:10.2307/1132208 